\title{
Formation of ice layers by infiltration and refreezing of meltwater
}

\author{
W.T. Pfeffer, ${ }^{1}$ N. F. Humphrey ${ }^{2}$ \\ ${ }^{1}$ Institute of Arctic and Alpine Research and Department of Geological Sciences, University of Colorado, Boulder, CO 80303-04.50, U.S.A. \\ ${ }^{2}$ Department of Geology and Geophysics, University of Wyoming, Laramie, WT 82071-3006, U.S.A.
}

\begin{abstract}
Melt-layer frequency and magnitude in polar and sub-polar ice cores have been interpreted as measures of past summer temperature, and calibrations have been proposed relating frequency of occurrence of ice layers in ice cores to past summer temperatures. But, observations in the percolation facies in Greenland and an analysis of the combined processes of meltwater infiltration and refreezing of water in snow indicate that, in addition to unusually high rates of meltwater input, formation of ice layers will also be facilitated by unusually cold initial conditions or early onset of melt. Uniform warming of both summer and winter conditions has the opposite effect and suppresses ice-layer formation in favor of uniform wetting and refreezing of the snow pack. Numerical modeling of infiltration and refreezing at a stratigraphic fine-to-coarse transition allows quantification of the effects of significant parameters (initial temperature, grain-size and density contrast across the stratigraphic transition, water-input rate and minimum impermeable-layer thickness). Calculations are made to distinguish threshold values of parameters at which infiltration progresses faster than refreezing, resulting in a break-through of water across the stratigraphic transition, from values leading to the formation of an ice layer when refreezing progresses faster than infiltration.
\end{abstract}

\section{INTRODUGTION}

The frequency of occurrence and thickness of ice layers in polar and sub-polar ice cores have been used as measures of past summer temperatures (Langway, 1967; Herron and others, 1981; Koerner and Fisher, 1990; Alley and Anandakrishnan, 1995), and calibrations have been proposed which relate a specific change in past summer temperature to a change in the frequency of ice layers or change in the fraction of annual layers occupied by melt-layer ice (Koerner and Fisher, 1990; Alley and Anandakrishnan, 1995). However, a comparison between quantitative measures of meltlayer occurrence and an independent indicator of summer temperature, such as July insolation, shows discrepancies which suggest that ice layers may reflect elements of climatic variability more complex than summer temperatures alone. Alley and Anandakrishnan (1995) noted an abrupt decrease in the occurrence of ice layers in the GISP2 (Greenland Ice Sheet Project 2) ice core from central Greenland at c. 9 ka (early Holocene), despite a Holocene maximum in July insolation at this time. Ice layers may have been present but invisible in the early Holocene ice owing to enclathratization of air bubbles in the GISP2 core (variations in bubble content make the ice layers visible in cores below the firnice transition), but Koerner and Fisher (1990) noted the same absence of melt layers in the early Holocene ice in a core from Ellesmere Island where the total core depth was only $127 \mathrm{~m}$ and enclathratization of bubbles did not occur. Koerner and Fisher also noted the discrepancy between ice-layer frequency and July insolation.

We propose here that the frequency and magnitude of melt layers are not simply determined by infiltration of meltwater arising from warm summer temperatures but by the interaction between meltwater input and initial (premelt) snow conditions, and that the appearance of melt layers in ice cores contains information about seasonal and intra-seasonal climatic variability as well as summer temperatures.

\section{FIELD OBSERVATIONS}

As an example of the pattern of variability in ice-layer structure under changing conditions of summer infiltration, we present a summary of stratigraphy mapped in August 1991 along a surface traverse following a segment of the EGIG line (Hofmann, 1986) in West Greenland, covering the percolation and soaked facies above the equilibrium line. Facies terms have been defined in Benson (1962) and in Williams and others (1991). The traverse covered approximately $40 \mathrm{~km}$, $\left(69^{\circ} 51^{\prime} 00^{\prime \prime} \mathrm{N}, 47^{\circ} 16^{\prime} 30^{\prime \prime} \mathrm{W}\right.$ to $69^{\circ} 43^{\prime} 11^{\prime \prime} \mathrm{N}$ to $\left.48^{\circ} 6^{\prime} 02^{\prime \prime} \mathrm{W}\right)$, along which elevations ranged from $1900 \mathrm{~m}$ (middle to upper range of the percolation facies) to $1640 \mathrm{~m}$ (lower range of the soaked facies). Measurements were made at intervals of $c$. 1-3 km of ice-layer location, approximate thickness and lateral variability down to a depth of c. $1.5 \mathrm{~m}$. Full pit profiles of stratigraphy, density, temperature, liquid-water content to c. $2 \mathrm{~m}$ depth were made at c. $5 \mathrm{~km}$ intervals along the traverse. Full pit results at four locations along the transect are shown in Figure 1.

Density and water-content profiles were made with the Finnish "snow-fork" dielectric device (Sihvola and Tiuri, 1986). The snow-fork samples a region approximately $2 \mathrm{~cm}$ in diameter around the probe and the density and watercontent values are displayed as points in the figure rather 

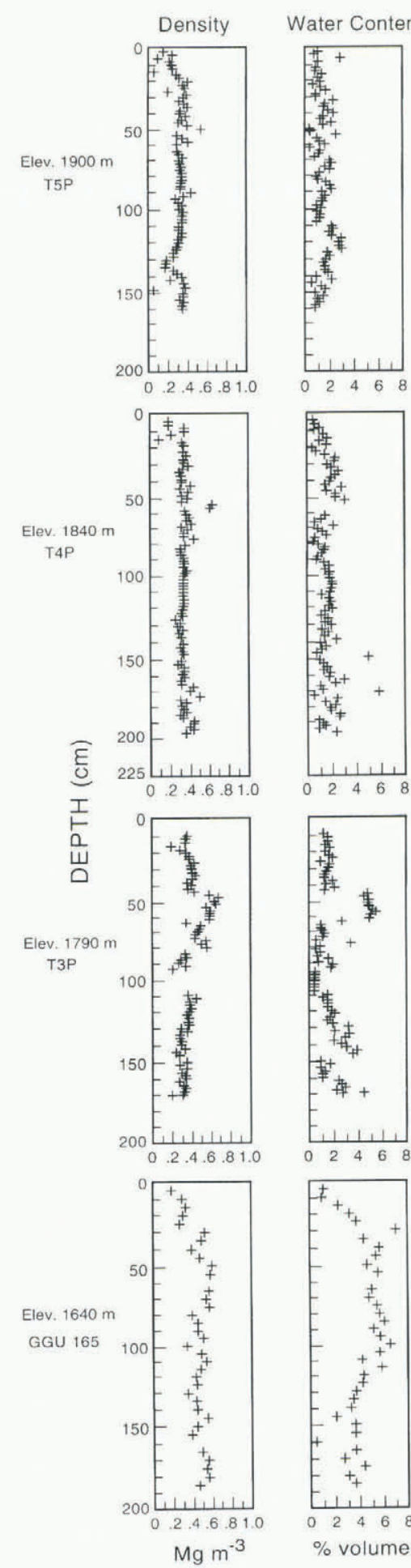
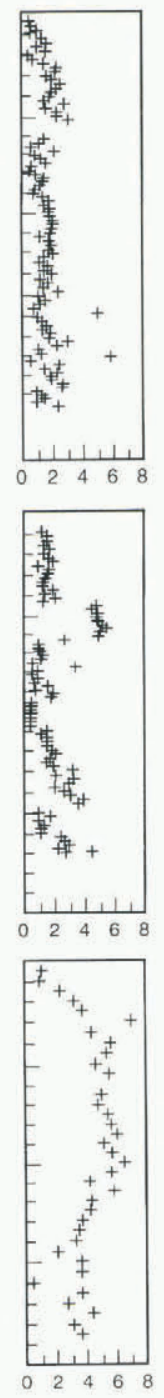

$\%$ volume
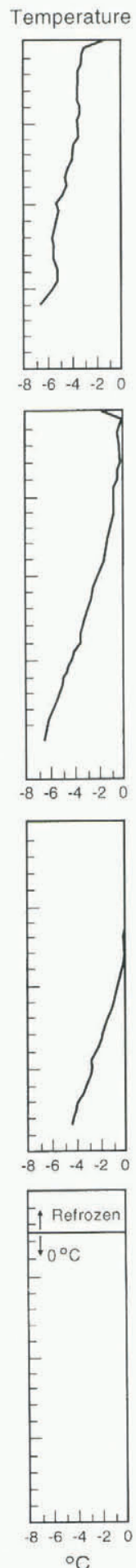

${ }^{\circ} \mathrm{C}$
Stratigraphy
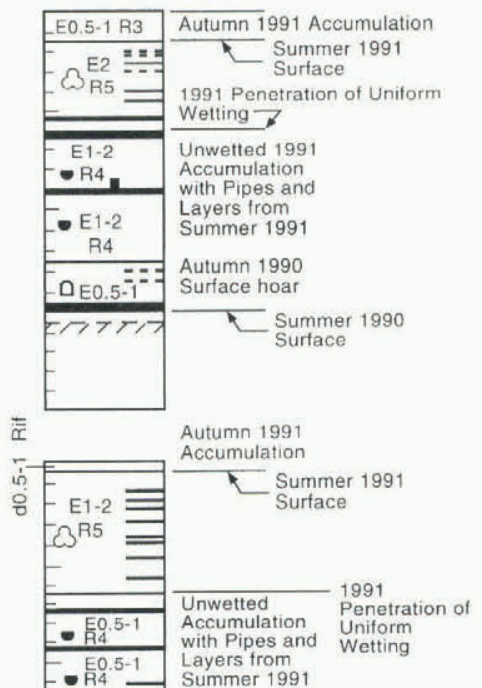

$-\mathrm{R} 4$ Summer 1991
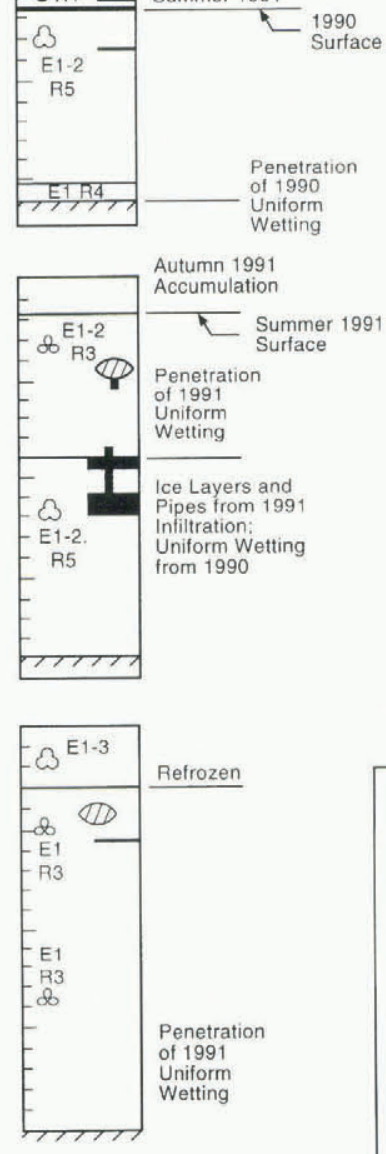

Fig. 1. Stratigraphy in percolation facies at four elevations along the EGIG line, West Greenland, observed at the end of the 1991 melt season.

than over depth intervals. Accuracy of the snow fork is nominally $\pm 5 \%$ for density in dry snow and $\pm 2 \%$ (of void volume) for liquid water and is additionally subject to errors arising from ionic contaminants in the snow. In practice, the snow fork appears to be sensitive only to large variations in water content. Measurements of density and water content as determined by the snow fork are shown in Figure 1, where at the highest site $(1900 \mathrm{~m})$ measured liquid-water content is seen to be as high as $2-3 \%$ by void volume despite the presence of sub-freezing temperatures as low as $-7^{\circ} \mathrm{C}$. Experimental and field comparisons of the snow fork with the Denoth dielectric device have been made (Williams and org/10.3189/1998AoG26-1-83-91 Published online by Cambridge University Press others, 1996) which show that, under controlled conditions, measurements of water content as made by the two devices do not differ by a statistically significant margin. The value of the snow-fork measurements remains an open question but we do not rely on the accuracy of the absolute values determined by the snow fork for the present purpose. Values derived from the snow-fork measurements are not a part of the quantitative modeling presented and we use the values only to investigate the qualitative pattern of density and water content over depth and in comparison to measured stratigraphy and temperature.

The four sites displayed in Figure 1 show a transition 
from partial infiltration of the current year's accumulation at the highest site $(1900 \mathrm{~m})$ to full wetting of several year's accumulation at the lowest site $(1640 \mathrm{~m})$. At the time of the observations, the summer melt season had essentially concluded, with refreezing of summer-wetted snow complete at 1900 and $1840 \mathrm{~m}$, and in progress at 1790 and $1640 \mathrm{~m}$.

We refer below to "full" wetting; this condition refers to the state in which the snow temperature is everywhere at the melting point and liquid water is present everywhere at some saturation. The liquid-water content throughout the uniformly wetted snow is unknown beyond what is shown by the snow-fork measurements but, in general, heterogeneous saturation and preferred flow paths are known to develop in snow at $0^{\circ} \mathrm{C}$ (e.g. Colbeck, 1979; Kattelmann, 1989; Conway and Benedict, 1994). However, the heterogeneity is less than in sub-freezing snow and, most importantly for the present discussion, heterogeneous flow paths within uniformly wetted snow do not produce ice layers since no subfreezing snow is present adjacent to highly saturated layers to provide a heat sink for released latent heat of freezing.

The stratigraphy at $1900 \mathrm{~m}$ shows the classical pattern of the percolation facies: partial wetting of the current year's accumulation by propagation of a uniform wetting front $(15-60 \mathrm{~cm}$ depth) and unwetted snow from the current year below the depth of full infiltration $(60-125 \mathrm{~cm})$. The fully infiltrated snow between 15 and $60 \mathrm{~cm}$ is characterized by large melt-freeze grain clusters and R5 hardness. The snow between 60 and $125 \mathrm{~cm}$ is smaller-grained, softer (R4) and shows some evidence of faceting. Within the $60-125 \mathrm{~cm}$ unit are several large ice layers delivered by pipes (observed) from wet layers higher in the snow during the melt season (the $60-125 \mathrm{~cm}$ unit is "unwetted" in the sense that it was not exposed to full infiltration; water was delivered to this unit but only in isolated pipes and ice layers). The previous year's summer surface lies at $150 \mathrm{~cm}$, at the base of an ice layer $(145-150 \mathrm{~cm})$ produced by the current summer's melt. Ice layers of various sizes are abundant throughout the stratigraphy.

At $1840 \mathrm{~m}$, a largely identical pattern to $1900 \mathrm{~m}$ is shown: full wetting from 5 to $70 \mathrm{~cm}$, unwetted accumulation with ice layers and pipes between 70 and $126 \mathrm{~cm}$, with the previous year's summer surface and fully wetted accumulation below $(126-210 \mathrm{~cm})$. As at $1900 \mathrm{~m}$, ice layers are abundant throughout the stratigraphy. Note also that the thicker-ice layers at both sites are concentrated in the lower unwetted units, while the upper fully wetted units contain more numerous but smaller layers. This is because the lower thicker-ice layers are formed by delivery from pipes, while the upper layers are mostly formed by delivery from full infiltration. The distinction between layers formed by these two processes has also been discussed by Pfeffer and Humphrey (1996) and will be discussed further below.

The stratigraphic picture changes at $1790 \mathrm{~m}$. Full wetting extends at this site to the complete depth of the current year's accumulation (soaked facies). The previous year's summer surface was not clear at this site but the refrozen wetted snow between $90 \mathrm{~cm}$ and the base of the pit at $190 \mathrm{~cm}$ is inferred to be at least in part full wetting from the previous year. Small ice layers are evidently rare or absent at this site, with ice layering confined mostly to a small number of very large and discontinuous ice layers, lenses and pipes. Refreezing at this site has not commenced but the refreezing process cannot produce ice layers after the time of observation from the conditions at the time of obser- vation: the fully wetted snow has created a steady-state (but not necessarily homogeneous) hydraulic pathway for water and no mechanism other than isolated refreezing at depth can create a hydraulic barrier to flow on which to build up a saturated layer to form an ice layer. Isolated freezing cannot occur from the conditions at the time of observation either, since in its isothermal state, no isolated heat sink exists in the fully wetted snow to freeze water along a distinct horizon.

The lowest site, at $1640 \mathrm{~m}$, shows even greater development of the uniformly wetted conditions seen at $1790 \mathrm{~m}$. Only one isolated ice lens was found, at $40 \mathrm{~cm}$, and a small ice layer at $55 \mathrm{~cm}$. Otherwise, the snow was homogeneously wet and free from any features of internal refreezing down to the pit depth of $200 \mathrm{~cm}$ (and as seen in a core below the pit, was wet to $270 \mathrm{~cm}$ depth). Surface refreezing from 0 to $28 \mathrm{~cm}$ occurred rapidly during a cold spell of several days duration.

For the purposes of the present analysis, the striking aspect of the variations in stratigraphy along the traverse is that internal ice layers are a more common element of the higher colder sites, where infiltration of summer melt is more limited than at lower warmer sites. This observation is not entirely compatible with the assumption made in paleoclimatic interpretations that increased ice-layer frequency, or fraction of mass in ice layers, is an indicator of greater meltwater input during anomalously warm summers.

These observations show how infiltration and refreezing change in character across a spatial gradient in climate, which is not identical to but is to a large degree analogous with how they may be expected to change in a temporal gradient in climate. We are assuming that we can infer the general character of the climatic gradient along the traverse from 1900 to $1640 \mathrm{~m}$ from existing mass-balance observations (e.g. Ohmura and Reeh, 1991; Letréguilly and others, 1991). Data are available for direct determination of the spatial gradient in energy balance in this region (Steffen and others, 1996), although an analysis of these data is beyond the scope of the present work.

\section{ANALYSIS}

We consider next the details of heat transfer and water flow at a stratigraphic barrier, the interaction between infiltration and refreezing of meltwater at a stratigraphic fine-tocoarse transition, and investigate what conditions promote the development of discrete internal ice layers vs infiltration across the boundary. Wankiewicz (1979) has summarized the effects of stratigraphy on water flow through a snowpack and has discussed the hydrology of stratigraphic boundaries which retard, accelerate or have no effect on flow. Among those boundaries which retard flow are fine-to-coarse transitions, where fine-grained snow overlies coarse-grained snow. The physical cause of the impedance stems from the behavior of unsaturated hydraulic conductivity at low water content, where fine-grained porous material becomes less conductive than coarse-grained material owing to the dominance of capillary effects in the smaller voids of the finegrained material. This effect has been discussed for snow by Wankiewicz (1979) and by Marsh (1991), and is also well known in the soils literature (see, e.g. Corey, 1977, fig. 4.7). While other stratigraphic boundaries are present in the 
snow pack considered here, we concentrate on fine-to-coarse transitions, because our experience here and elsewhere in Greenland (Pfeffer and Humphrey, 1996) indicates that these are probably the primary formation sites for ice layers in the percolation facies of Greenland. The tendency for ice layers to form at fine-to-coarse transitions has been noted by Wakahama (1968), although Marsh and Woo (1984) reported that in their observations all stratigraphic boundaries acted as impeding horizons.

Qualitatively, the formation of an ice layer at a stratigraphic boundary depends on the freezing process at the boundary interface occurring rapidly enough to create an impermeable (or very reduced permeability) ice layer before sufficient water has accumulated to force flow across the barrier. Liquid water is added on the fine (upper) side of the transition as flow from above feeds water to the interface and is simultaneously subtracted by refreezing. Latent heat released during refreezing is conducted to colder snow adjacent to the site of refreezing and reduces the temperature gradient driving refreezing. Water flow is also influenced by the refreezing process through reduction of void space and intrinsic permeability.

In the following analysis, we consider only the one-dimensional problem of water crossing a boundary from finegrained to coarse-grained material. However, stratigraphic boundaries in snow are highly heterogeneous and the infiltration and refreezing process produces correspondingly heterogeneous results along boundaries and a complex three-dimensional structure of ice layers, pipes and water pathways. In general, refreezing culminating in the production of a locally impermeable ice layer can be expected to occur over some fraction of the area of a sub-freezing impeding boundary, with break-through of water across the boundary occurring over the remaining area. The relative size of the permeable and impermeable areas depends upon the heterogeneity of grain-scale hydrological characteristics of the impeding boundary and upon the processes which we are modeling here. The observed proportions of permeable and impermeable areas (e.g. Benson, 1962; Marsh and Woo, 1984; Echelmeyer and others, 1992) range from negligible ice-layer formation (isolated ice glands) to negligible break-through (continuous massive ice layers).

Following formation of ice layers on parts of an impeding boundary, water draining on to impermeable parts of the boundary is diverted downslope (or laterally) until it encounters a place where water flow across the boundary is established. In this way, that part of the boundary occupied by ice layers forms a catchment area for adjacent drainage across the boundary, allowing substantial water flux past the boundary in a limited number of vertical drainage channels (pipes). Conditions which strongly favor the predominance of ice-layer formation over break-through result in a large fraction of the impeding boundary developing into an impermeable ice layer but, at the same time, focuses a large flux of water on to the small fraction of area where drainage across the boundary has been established. Highflux vertical drainage channels have a greater capacity to penetrate cold snow than uniform infiltration (Marsh and Woo, 1984; Pfeffer and Humphrey, 1996) and result in deeper but more heterogeneous infiltration of melt.

Consequently, the formation of a single ice layer, to which the modeling presented here applies, results ultimately not in sealing off the snowpack below the layer but in infiltration which is deeper and more heterogeneous than org/10.3189/1998AoG26-1-83-91 Published online by Cambridge University Press a uniform wetting-front advance. The number and variety of stratigraphic boundaries influences the number of potential sites for ice-layer formation but Arctic snowpacks typically contain a very large number of distinct stratigraphic units as a consequence of wind transport and deposition, and availability of impeding boundaries is not a limiting factor.

\section{Infiltration}

Under unsaturated, two-phase (water and air) conditions, where inertial effects are negligible, water flux $u_{\mathrm{w}}$ (with dimensions of $L T^{-1}$ ) is given by the Darcy equation:

$$
u_{\mathrm{w}}=k_{\mathrm{w}} \mu_{\mathrm{w}}{ }^{-1}\left(\frac{\partial p_{\mathrm{c}}}{\partial z}+\rho_{\mathrm{w}} g\right)
$$

where $k_{\mathrm{w}}$ is the unsaturated permeability, $\mu_{\mathrm{w}}$ is the viscosity of water at $0^{\circ} \mathrm{C}, p_{\mathrm{c}}$ is the capillary pressure, $\rho_{\mathrm{w}}$ is density of water (at $0^{\circ} \mathrm{C}$ ), $g$ is gravity, and $z$ is the vertical coordinate. The unsaturated permeability $k_{\mathrm{w}}$ can be expressed in terms of intrinsic permeability $k$ and capillary pressure as

$$
k_{\mathrm{w}}=k\left(\frac{p_{\mathrm{d}}}{p_{\mathrm{c}}}\right)^{n \lambda}
$$

where $k_{\mathrm{w}}, p_{\mathrm{d}}, n$ and $\lambda$ are parameters which are characteristic of the given porous medium. The intrinsic permeability $k$ has been determined experimentally for snow as a function of density and grain-size by Shimizu (1970). For the exponent $n$ we use Colbeck and Davidson's (1973) value of 3.0, which we hold fixed. The parameters $p_{\mathrm{d}}$ (air-entry pressure) and $\lambda$ (Brooks-Corey parameter) have been measured by Wankiewicz (1976) for some different snow types but without good control on the characteristic grain-size of the snow. In order to have values of $p_{\mathrm{d}}$ and $\lambda$ which are measured for well-defined grain-sizes, we use values determined experimentally for sands of appropriate grain-size (Illangasekare and others, 1995; personal communication from G. Walser, 1997) to represent fine-grained and coarse-grained snow. These values are shown in Table 1 . The value of $p_{\mathrm{d}}$ for the coarse-grained side (represented by \#30 sand) is higher than the range of values given for snow by Wankiewicz (1976), who reported maximum values (from measurements of two snow samples) of $-650 \mathrm{~Pa}$. We investigated the effects of uncertainty in the values of $p_{\mathrm{d}}$ in the numerical calculation; these results are discussed below.

The capillary pressure $p_{\mathrm{c}}$ associated with the unsaturated hydraulic conductivity required to maintain a steady flux $u_{\mathrm{w}}$ under a given pressure gradient is greater in magnitude (more negative) in fine-grained snow than in coarsegrained snow. In order to preserve continuity of pressure across the fine-to-coarse transition, a pressure gradient ex-

Table 1. Sand hydrologic parameters adopted for fine- and coarse-grained snow

\begin{tabular}{ccccc}
\hline & $\begin{array}{c}\text { Grain-size } \\
\mathrm{mm}\end{array}$ & $\begin{array}{c}\lambda \\
\text { Brooks-Corey }\end{array}$ & $\begin{array}{c}p_{\mathrm{d}} \\
\mathrm{Pa}\end{array}$ & $\begin{array}{c}K_{\text {sat }} \\
\mathrm{cm} \mathrm{s}^{-1}\end{array}$ \\
\hline \#16 sand & 1.0 & 2.11 & $\begin{array}{c}345.0 \\
\text { (imbibition) } \\
1051.0\end{array}$ & 0.145 \\
(drainage)
\end{tabular}


ists where saturation rises in water accumulated on the fine (upper) side of the interface. The gradient in saturation approaching the transition can be calculated assuming steady flow using a method described by Corey (1977, p. 147); we take a simplified approach here by assuming that the water accumulating at the interface is initially stationary, so the pressure gradient is simply $\rho g$. From this, the depth of the gradient zone is

$$
Z_{\mathrm{w}}=\frac{\Delta p}{\rho g}=\frac{\left(p_{\mathrm{c}, 1}-p_{\mathrm{c}, 2}\right)}{\rho g}
$$

where $p_{\mathrm{c}, 1}$ and $p_{\mathrm{c}, 2}$ refer to capillary pressure in the fine and coarse layers, respectively, and are calculated in terms of the transmitted flux $u_{\mathrm{w}}$ :

$$
p_{\mathrm{c}}=p_{\mathrm{d}}\left(\frac{\mu_{\mathrm{w}} u_{\mathrm{w}}}{k \rho g}\right)^{-1 / n \lambda} .
$$

The capillary pressure $p_{\mathrm{c}}$ is calculated separately in the fine and coarse layers using corresponding values for $p_{\mathrm{d}}, k$ and $\lambda$.

The total water required to establish the saturation gradient is

$$
\begin{aligned}
\theta & =\phi S_{\mathrm{r}} Z_{\mathrm{w}}+\phi\left(1-S_{\mathrm{r}}\right) \int_{0}^{Z_{\mathrm{w}}}\left(p_{\mathrm{d}} / p_{\mathrm{c}}(\xi)\right)^{\lambda} \mathrm{d} \xi \\
& =\phi S_{\mathrm{r}} Z_{\mathrm{w}}+\phi\left(1-S_{\mathrm{r}}\right) \frac{p_{\mathrm{d}}^{\lambda}}{\rho g}\left[\frac{p_{\mathrm{c}, 1}^{1-\lambda}}{1-\lambda}-\frac{p_{\mathrm{c}, 2}^{1-\lambda}}{1-\lambda}\right]
\end{aligned}
$$

where $\phi$ is the bulk snow porosity, $S_{\mathrm{r}}$ is the irreducible saturation, taken to be $7 \%$ pore volume for all snow types (Colbeck and Davidson, 1973) and $p_{\mathrm{d}}$ and $\lambda$ take on values for fine-grained snow (represented by \#30 sand (Table 1)).

The time required to fill the saturation gradient can be determined in terms of the water-input rate to the interface and the rate of loss of water by refreezing at the interface. Under steady conditions in the snow above the impeding interface, the rate of water input to the interface is equal to the rate of surface meltwater production, $u_{\text {input }}$ (with dimensions of $L T^{-1}$ ), which we treat as a parameter in calculations. The rate of accumulation of liquid water $\dot{\theta}$ at the interface is equal to the water-input rate minus the rate of local refreezing:

$$
\dot{\theta}=u_{\text {input }}-\frac{\dot{q}}{\rho_{\mathrm{w}} L}
$$

where $\dot{q}$ is the heat release associated with freezing at the interface, $\rho_{\mathrm{w}}$ is the density of water and $L$ is the latent heat of fusion. The time required for sufficient water to accumulate to establish the saturation gradient and allow flow across the transition, or time to break-through, $t_{\mathrm{B}}$, can then be calculated if the input and loss rates $u_{\text {input }}$ and $\dot{q}$ are known.

\section{Refreezing}

The rate of refreezing at the fine-to-coarse transition is determined by calculating the time-varying heat flux conducted away from a boundary held at $0^{\circ} \mathrm{C}$ into a medium of initial uniform sub-freezing temperature $-T$. This is done for two geometries: one in which heat is conducted away from the freezing interface on one side only (corresponding to freezing at the edge of a uniformly infiltrating wetting front) and another in which heat is conducted away from the site of freezing into cold snow above and below the wet layer (corresponding to freezing of water injected along a fine-to-coarse transition from a pipe source). For one-sided freezing, the heat flux (with dimensions of $E L^{-2} T^{-1}$ ) as a function of distance $z$ from the $0^{\circ} \mathrm{C}$ boundary and time $t$ following imposition of $0^{\circ} \mathrm{C}$ at the boundary is (e.g. Carslaw and Jaeger, 1959):

$$
\dot{q}(z, t)=\frac{\sqrt{\rho c k}}{2 \sqrt{t}} T \exp \left(-\frac{z}{2 \sqrt{\kappa t}}\right)
$$

where $\rho$ is the snow density, $c$ is the heat capacity of ice, $k$ is the density-dependent thermal conductivity of snow, $\kappa$ is the thermal diffusivity of snow and $T$ is the positive magnitude of the initial sub-freezing snow temperature. The accumulated heat conducted away from the interface (at $z=0$ ) is then

$$
q(0, t)=\int_{0}^{t} \dot{q}(0, t) \mathrm{d} t=T \sqrt{\rho c k} \sqrt{t} .
$$

If $q_{\mathrm{F}}$ is the amount of heat release involved in the refreezing of an amount of ice sufficient to create an impermeable (or substantially reduced permeability) horizon, then the time $t_{\mathrm{F}}$ to the creation of an impermeable horizon, or the "freeze-off" time, is

$$
t_{\mathrm{F}}=\frac{1}{\rho c k}\left(\frac{q_{\mathrm{F}}}{T}\right)^{2} .
$$

For two-sided conduction, with heat being conducted into sub-freezing snow on both sides of the wet layer, the heat flux is

$$
\begin{aligned}
\dot{q}_{1}(z, t)+\dot{q}_{2}(z, t)= & \frac{\sqrt{\rho_{1} c k_{1}}}{2 \sqrt{t}} T_{1} \exp \left(-\frac{z}{2 \sqrt{\kappa_{1} t}}\right) \\
& +\frac{\sqrt{\rho_{2} c k_{2}}}{2 \sqrt{t}} T_{2} \exp \left(-\frac{z}{2 \sqrt{\kappa_{2} t}}\right)
\end{aligned}
$$

where the subscripts 1 and 2 refer to the fine- and coarsegrained snow layers, respectively. The accumulated heat conducted away from the interface is

$$
q(0, t)=\left[T_{1} \sqrt{\rho_{1} c k_{1}}+T_{2} \sqrt{\rho_{2} c k_{2}}\right] \sqrt{t}
$$

and the time to freeze-off is

$$
t_{\mathrm{F}}=\frac{q_{\mathrm{F}}^{2}}{\left[\sqrt{\rho_{1} c k_{1}} T_{1}+\sqrt{\rho_{2} c k_{2}} T_{2}\right]^{2}} .
$$

Note that for the special case, where the snow density and temperature are the same on both sides of the interface, the time to two-sided freeze-off reduces to

$$
t_{\mathrm{F}}=\frac{q_{\mathrm{F}}^{2}}{[2 \sqrt{\rho c k} T]^{2}}
$$

or one-fourth of the time for one-sided freeze off. The rate of freezing is faster for two-sided freeze-off, because the area across which heat is transferred is doubled and with the heat flux distributed over twice the area, the temperature gradient is reduced more slowly.

The total latent-heat release required to achieve an impermeable horizon remains to be determined. We estimate what minimum vertical extent of ice will stop or substantially slow the liquid-infiltration process by considering an ice layer of thickness $D$ consisting of ice at density $\rho_{\text {imp. }}$. This layer releases an amount of heat equal to

$$
q_{\mathrm{F}}=L\left(\rho_{\text {imp }}-\rho_{1}\right) D
$$

where $L$ is the latent heat of fusion and $\rho_{1}$ is the initial snow density in the fine-grained layer where the ice forms. We chose $\rho_{\text {imp }}$ to be the pore close-off density of $0.83 \mathrm{Mg} \mathrm{m}^{-3}$ and treat $D$ as a parameter in the calculations. 
One-sided freezing

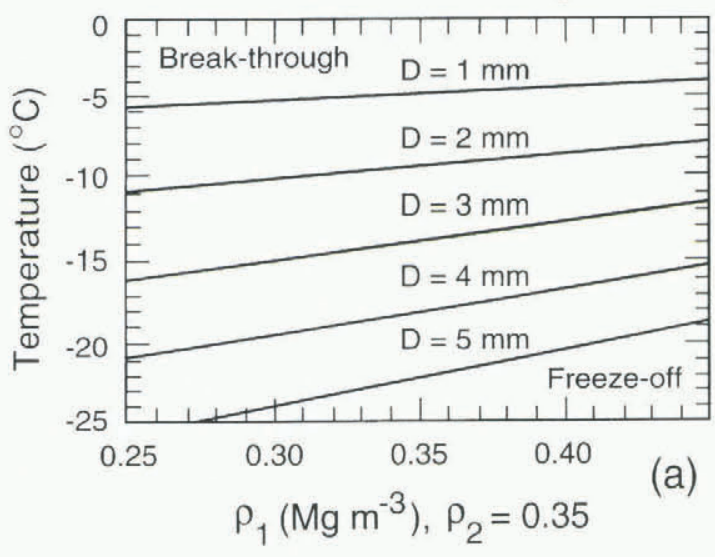

One-sıded freezing

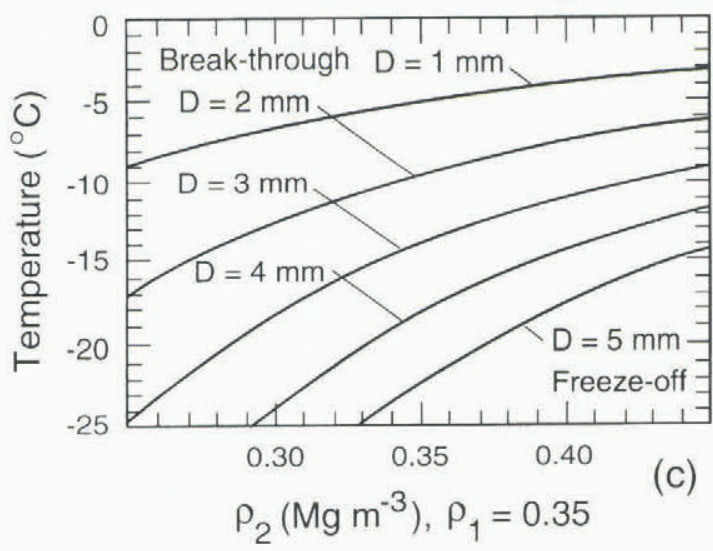

One-sided freezing

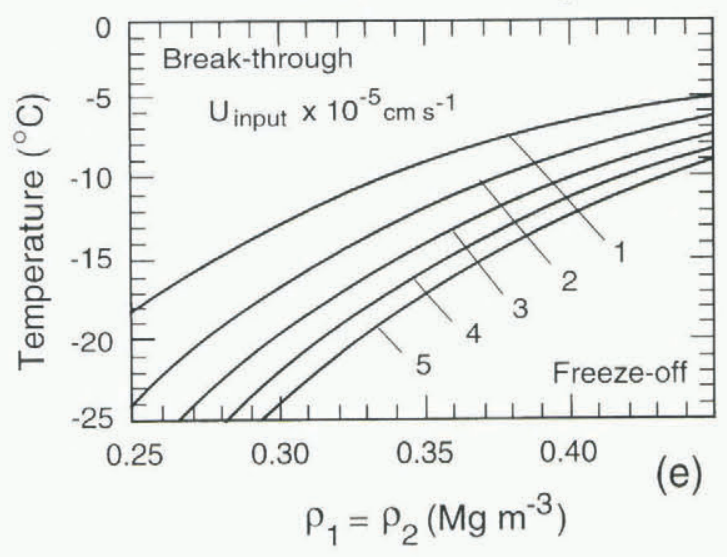

Two-sided freezing

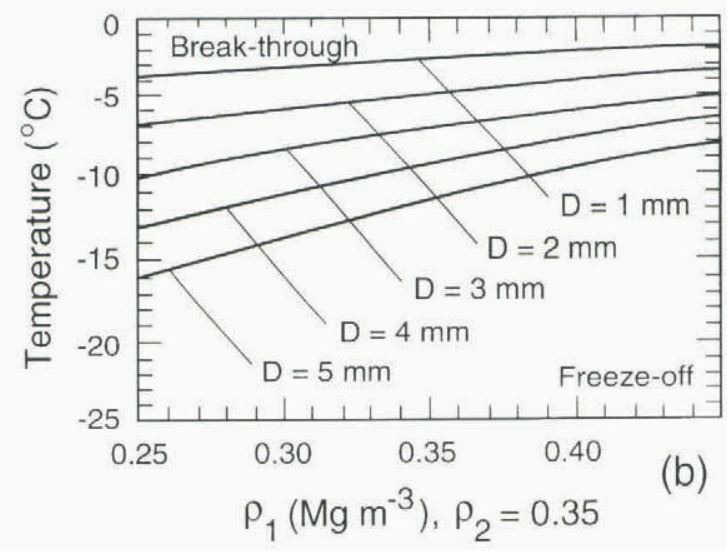

Two-sided freezing

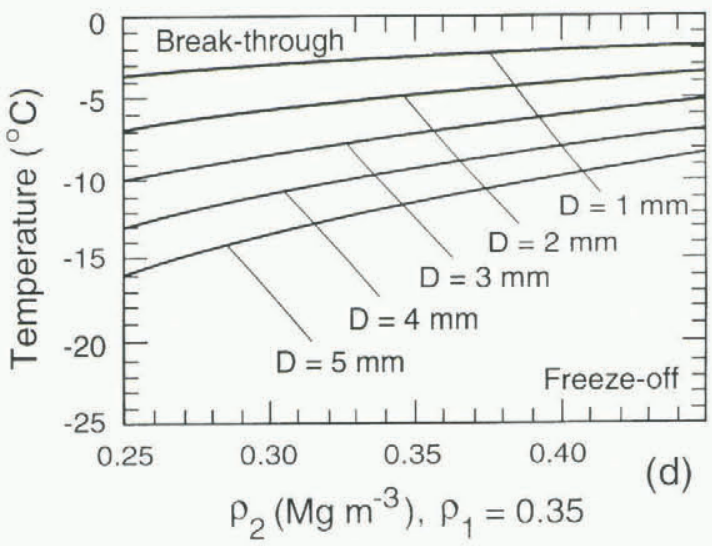

Two-sided freezing

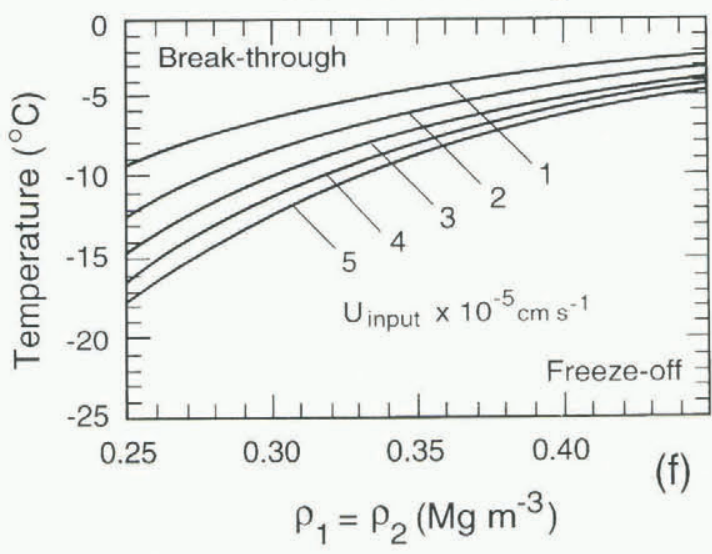

Fig. 2. Nomograms displaying model results. Temperature-density parameter spaces are divided by curves for selected values of a third parameter into regions where infiltration dominates freezing ("break-through") above the curve, and regions where freezing dominates infiltration ("freeze-off") below the curve. The third parameter values shown are minimum impermeable-layer thick-

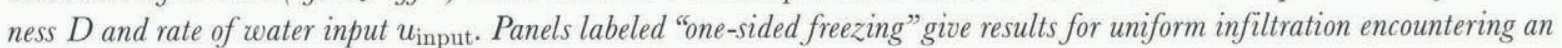
horizon with sub-freezing snow below; panels labeled "two-sided freezing" give results for water injected from a pipe source along an horizon with sub-freezing snow above and below.

\section{Model calculations}

We calculated the time to break-through $t_{\mathrm{B}}$, and the time to freeze-off, $t_{\mathrm{F}}$, based on the theory described above, for values of $\rho$, grain-size and $T$ describing the fine-grained and coarse-grained layers, and for a range values of the parameters $u_{\text {input }}$ and $D$. Break-through of water across the stratigraphic horizon is the final result of the combined processes if $t_{\mathrm{B}}<t_{\mathrm{F}}$; alternatively, an ice layer is the result if $t_{\mathrm{F}}<t_{\mathrm{B}}$. The results of the calculations are shown in Figure https://doi.org/10.3189/1998AoG26-1-83-91 Published online by Cambridge University Press
2 , in the form of nomograms indicating regions of the parameter space in which either break-through or freeze-off dominates. Each of the six graphs in Figure 2 shows a region of $T-\rho$ parameter space subdivided by a family of curves corresponding to selected values of a third parameter. The path of the curve for any one value of the third parameter divides the $T-\rho$ space into a region where break-through dominates $\left(t_{\mathrm{B}}<t_{\mathrm{F}}\right)$ above each curve and a region where freeze-off dominates $\left(t_{\mathrm{F}}<t_{\mathrm{B}}\right)$ below each curve. Figure $2 a-d$ shows break-through vs freeze-off for combinations of 
Table 2. Minimum and maximum times $(h)$ to break-through or freeze-off for the six nomograms $(a)-(f)$ in Figure 2

\section{Minimum \\ Time (h) \\ Maximum}

Time $(\mathrm{h})$

$\begin{array}{rrrrrr}5.2 & 3.5 & 6.2 & 3.6 & 6.7 & 5.0 \\ 15.5 & 15.1 & 17.5 & 18.0 & 37.0 & 42.0\end{array}$

$T, \rho$ and the minimum ice-layer thickness $D$; Figure $2 \mathrm{e}$ and f shows break-through vs freeze-off for combinations of $T, \rho$ and water-input rate $u_{\text {input }}$. Figure $2 \mathrm{a}$, c and e shows results for one-sided freezing and Figure $2 b, d$ and $f$ shows results for two-sided freezing.

The maximum and minimum times to culmination of the break-through/freeze-off process for each of the six nomograms are shown in Table 2. The times should be compatible with the time-scale of the infiltration process in Nature, where steady infiltration is unlikely to occur for time periods greater than 24 hours, since the production of surface melt is strongly forced by daily cycles in temperature and solar radiation. As can be seen in Table 2, the maximum times for panels $2 \mathrm{e}$ and fare greater than 24 hours, although times greater than 24 hours occur in only $13 \%$ of the calculated outcomes for these two cases. In these cases, at least, a more realistic treatment in future calculations can be achieved by cycling the water input and allow refreezing to continue without infiltration for a part of the 24 hour period.

We choose ranges of $1-5 \mathrm{~mm}$ for $D$ and $1 \times 10^{-5}$ to $5 \times 10^{-5} \mathrm{~cm} \mathrm{~s}^{-1}$ for $u_{\text {input. }}$ The minimum ice-layer thickness $D$ is not well constrained by observations. We chose the range of values $1-5 \mathrm{~mm}$ in part, because it represents thicknesses equal to several grain diameters (and, roughly, void diameters) and also because pipes are observed to descend from ice layers as small as c. $5 \mathrm{~mm}$, indicating that ice layers of this size are diverting water laterally. We have noted that $D$ represents only the thickness at which the water-flow process is substantially interrupted; the freezing process may continue past this point and the final ice-layer thickness may be substantially greater than $D$. The range of water input is chosen to bracket a typical value for melt rate $\left(3 \times 10^{-5} \mathrm{~cm} \mathrm{~s}^{-1}\right)$ at a mid-latitude Greenland site within the percolation facies, based on simple surface-energy balance considerations.

In Figure $2 \mathrm{a}$ and $\mathrm{b}$, the density $\rho_{1}$ of the fine-grained (upper) side of the interface is varied, while the density $\rho_{2}$ of the coarse-grained (lower) side is held fixed at $0.35 \mathrm{Mg} \mathrm{m}^{-3}$. The temperature variation refers to the lower cold side of the interface only for one-sided freezing in Figure $2 \mathrm{a}$ and to the temperature of both sides of the interface in two-sided freezing. The paths of minimum ice-layer thickness $D$ follow nearly straight lines in $T-\rho$ space, with greater values of $D$ placing greater demands on the freezing process and, as would be expected, displacing the breakthrough/freeze-off boundary downward and expanding the region of break-through. The variable density in the fine layer $\left(\rho_{1}\right)$ affects the break-through/freeze-off process nonlinearly in the amount of water required to cross the stratigraphic boundary (Equation (5)), but, more dominantly and linearly, in the amount of ice initially present on the upper side of the boundary. This dominance causes the paths of $D$ to be straight, while the corresponding paths in the other panels can be seen to be curved. Comparison of Figure $2 \mathrm{a}$ (one-sided freezing) and b (two-sided freezing) shows the effect of the greater rate of freezing for the twosided process. For example, at $T=-15^{\circ} \mathrm{C}$ and $\rho_{1}=$ $0.30 \mathrm{Mg} \mathrm{m}^{-3}$, one-sided freezing can lead to freeze-off only if a $3 \mathrm{~mm}$ ice layer is sufficient to create an impermeable horizon, while two-sided freezing can lead to freeze-off,even if the minimum requirement for impermeability is greater than $5 \mathrm{~mm}$.

Figure 2c and d shows break-through vs freeze-off for the same ranges of $T$ and $D$ but with the density $\rho_{1}$ of the finegrained (upper) side of the interface held fixed at $0.35 \mathrm{Mg} \mathrm{m}^{-3}$ and the density $\rho_{2}$ of the coarse-grained (lower) side varied. In this case, the paths of the minimum ice-layer thickness $D$ are curved, reflecting the dominance of the non-linearity of $\rho_{2}$ in the calculation of the amount of water required to cross the stratigraphic boundary. Beyond this feature, the most significant difference between the curves for variable $\rho_{1}$ (Fig. $2 \mathrm{a}$ and b) and those for variable $\rho_{2}$ (Fig. 2c and d) is the small counter-clockwise rotation of the curves in Figure 2c relative to those in Figure 2a. The curves in Figure $2 \mathrm{c}$ are depressed below the values in Figure 2a for $\rho_{2}$ below 0.35 (the fixed value in Figure 2a) and are elevated for $\rho_{2}$ above 0.35 . The change is due to the dependence of thermal conductivity on density: lower thermal conductivity at lower density slows the freezing process and expands the region of break-through, while higher thermal conductivity at increased density speeds the freezing process and expands the region of freeze-off.

Figure $2 \mathrm{e}$ and $\mathrm{f}$ shows the effect of varying the water input rate. In this case, $\rho_{1}$ and $\rho_{2}$ are set equal and varied together. Increased rates of water input $u_{\text {input }}$ expand the region of break-through in $T-\rho$ space, as would be expected, but not without limit: the effect of an increase in $u_{\text {input }}$ is greater at lower values of $u_{\text {input }}$. This is because $u_{\text {input }}$ is rate-limiting at low rates of water input but not fully rate-controlling, as expressed in Equation (6). The relatively close spacing of the curves for different values of $u_{\text {input }}$ indicate that this parameter is not an especially effective control on the break-through/freeze-off process. For example, in Figure $2 \mathrm{f}$, the break-through/freeze-off boundary for $u_{\text {input }}=2 \times 10^{-5} \mathrm{~cm} \mathrm{~s}^{-1}$ lies at $T=-8.5^{\circ} \mathrm{C}$ for $\rho=$ $0.30 \mathrm{Mg} \mathrm{m}^{-3}$. A doubling of $u_{\text {input }}$ to $4 \times 10^{-5} \mathrm{~cm} \mathrm{~s}^{-1}$ displaces the break-through/freeze-off boundary downward to $T=-1^{\circ} \mathrm{C}$ for the same density. Leaving $u_{\text {input }}$ fixed at $2 \times 10^{-5} \mathrm{cms}^{-1}$ and reducing density accomplishes the same displacement of the break-through/freeze-off boundary (from $-8.5^{\circ}$ to $-11^{\circ} \mathrm{C}$ ) for a density change of only $13 \%$ from 0.30 to approximately $0.26 \mathrm{Mg} \mathrm{m}^{-3}$. The doubling of $u_{\text {input }}$ is a significant variation in energy balance, while a $13 \%$ change in density is well within observed intra-seasonal variability.

The air-entry pressure $p_{\mathrm{d}}$ and its contrast across the fineto-coarse transition is among the most important hydrological parameters to be specified for the break-through/ freeze-off process, but it is probably the least well-known from measurements in snow. We calculated the effect on the results of $10 \%$ variations in $p_{\mathrm{d}}$ for both the fine and coarse sides of the interface. Representative results are shown in Figure 3. The solid curves are the result (from Fig. 2e) for one-sided freeze-off, with $\rho_{1}=\rho_{2}=0.35 \mathrm{Mg} \mathrm{m}^{-3}$ and $U_{\text {input }}=3 \times 10^{-5} \mathrm{~cm} \mathrm{~s}^{-1}$. The shaded area surrounding the single curves in Figure $3 \mathrm{a}$ (variation of $p_{\mathrm{d}}$ for the fine- 
One-sided freezing

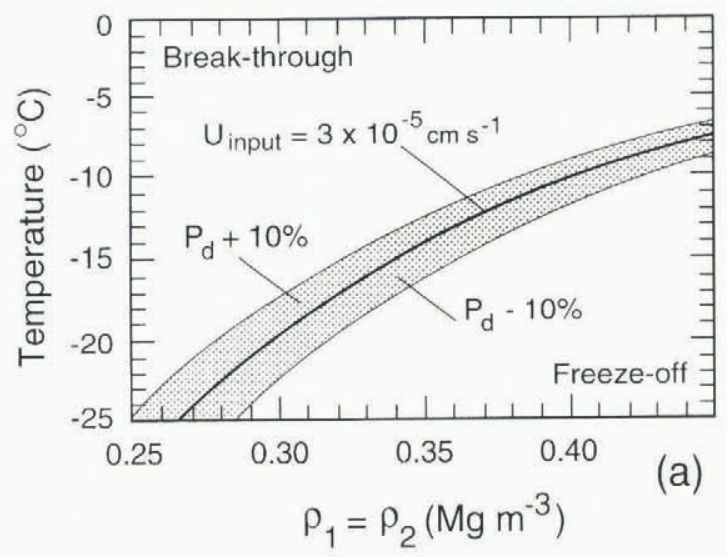

$\pm 10 \%$ Variation in $p_{d}$ of fine layer
One-sided freezing

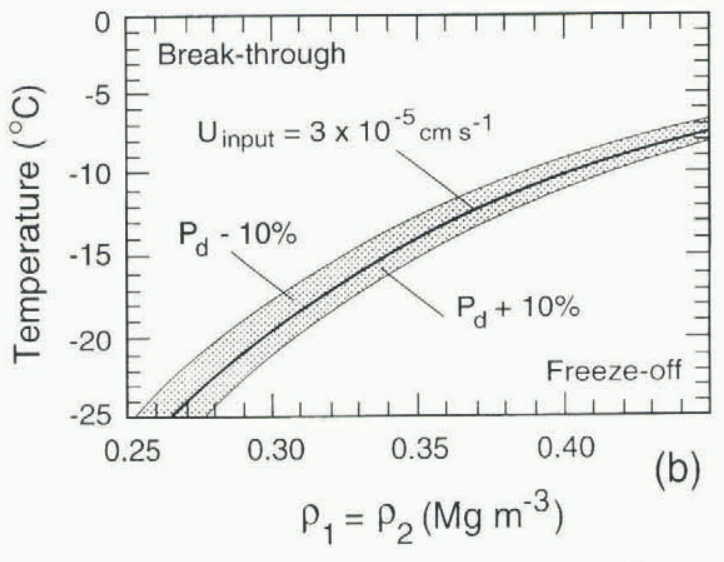

$\pm 10 \%$ Variation in $p_{d}$ of coarse layer

Fig. 3. Nomograms showing the effect of $10 \%$ variations in air-entry pressure. (a) shows the effect of variations of $p_{\mathrm{d}}$ in the finegrained (upper) side of the stratigraphic horizon, while (b) shows the effects of variations in the coarse-grained (lower) side. The solid curve is for one-sided freeze-off, with $\rho_{1}=\rho_{2}=0.35 \mathrm{Mg} \mathrm{m}^{-3}$ and $U_{\text {input }}=3 \times 10^{-5} \mathrm{~cm} \mathrm{~s}^{-1}$. The shaded areas show how the curve separating break-through from freeze-off is displaced by the variations in $p_{\mathrm{d}}$.

grained material) and Figure $3 \mathrm{~b}$ (for the coarse-grained material) show the range of displacement of the curve for a $10 \%$ increase and decrease in $p_{\mathrm{d}}$. Note that the direction of displacement of the curve is opposite in Figure $3 a$ and $b$ : this is consistent with the fact that variations resulting in a reduction in contrast across the interface result in an expansion of the region of break-through in $T-\rho$ space, while an increase in contrast will expand the region of freeze-off. The displaced curves still lie within a part of the $T-\rho$ space relevant to the present investigation. We also repeated the calculations with $p_{\mathrm{d}}$ for the fine-grained material reduced to $-650 \mathrm{~Pa}$ (Wankiewicz's reported maximum value); this resulted in a somewhat greater expansion of the region of break-through than shown in Figure 3 but the line dividing break-through from freeze-off still lies within a relevant part of the space. All parameters relating various hydrological properties to water content are intrinsically very difficult to measure in a controlled fashion in snow, because of thermodynamic influences on grain-size, water content and capillary pressure. Better values of $p_{\mathrm{d}}$ as a function of grainsize would be very desirable to improve this analysis but how such measurements will be performed is unclear.

All the nomograms in Figure 2 show in a general way the expected pattern of refreezing dominating breakthrough for conditions of colder initial temperature and greater density. Variations in minimum impermeable layer thickness $D$ and input rate $u_{\text {input }}$ displace the breakthrough/freeze-off boundary towards break-through when the variations act to place greater demands on the freezing process or ease demands on the break-through process and displace the boundary towards freeze-off for variations acting in the opposite sense. The region of the $T-\rho-D-u_{\text {input }}$ parameter space containing the breakthrough/freeze-off boundaries also brackets values of the parameters observed and inferred for the percolation facies. However, the relationships between break-through, freezeoff and the parameters considered is complex and, in particular, does not show simply that break-through dominates freeze-off under conditions of increased meltwater input without regard to other parameters. The model results support the hypothesis developed above that the distribution of ice layers observed over a part of the percolation facies along the EGIG line is in part a consequence of the close competition between the processes of break-through and freeze-off. Evidently, an increased frequency of occurrence of ice layers at one site relative to another, or at one site relative to the same site at a different time, may be the consequence of (keeping other model parameters fixed): (1) greater meltwater input (the cause typically assumed in paleoclimatic interpretations); (2) colder initial conditions (possibly due to a colder winter or earlier onset of spring melt); or (3) greater initial density in either the fine-grained or coarse-grained layer. While variations in minimum impermeable layer thickness $D$ have a significant effect, this parameter has been varied only because the most realistic value is not known. It is unlikely that this is an "environmental" variable with a well-defined value which changes in space and time in response to environmental forcing. To the extent that the value might vary as a function of, say, grain type or grain age, the change in value would most likely affect the heterogeneity of break-through along stratigraphic fine-to-coarse transitions and influence other quantities such as typical inter-pipe spacing which have influences on the development of ice layers which are not dealt with here.

From the perspective of applications to paleoclimate analyses, the most significant conclusion, derived from the model results, and supported by the EGIG-line observations, is that increased frequency of ice layers will not be a consequence of uniform warming in summer and winter (best seen in the transition in ice-layer frequency with descending elevation along the EGIG line) but is most likely a consequence of an increased contrast between initial snow temperature (a measure of winter temperature) and summer melt rate (a measure of summer temperature). The contrast may arise from an increase in summer temperature, together with a constant winter temperature, or a decrease in winter temperature with a constant summer temperature, or both (increased seasonal amplitude in temperature), or from a change in the time of onset of spring melting with winter and summer average temperatures remaining unchanged. 


\section{CONGLUSIONS}

Observations in the percolation facies between 1650 and $1900 \mathrm{~m}$ in West Greenland indicate that the relationship between frequency of occurrence of ice layers in the snowpack and climate (and summer temperatures in particular) is more complex than typically assumed in the paleoclimatic interpretation of ice layers in ice cores taken from relatively wet sites. The process of ice-layer formation was studied analytically by modeling the competition between infiltration of water across a stratigraphic boundary in layered porous media and the loss of water by refreezing. In the absence of definite measurements of the Brooks-Corey parameter $\lambda$ and entry pressure $p_{\mathrm{d}}$ for snow of different grain-sizes, values were adopted from measurements in sand. Despite the uncertainty in the specific values of the model calculations using parameter values from sands, the results demonstrate the principles and facilitate the discussion of how ice layers originate. Better experimental values of hydrological parameters for snow of different grain-sizes will improve the present calculations, as will direct experimental or field observations of the freezing process at impeding horizons in layered snowpacks. However, the essential physical phenomena controlling the combined processes of infiltration and refreezing at a fine-to-coarse transition are well-represented. Model results agree qualitatively with the conclusions from the Greenland observations and indicate that increased frequency of ice layers in snow is the product of greater temperature contrast between winter conditions and summer conditions. The result has implications for paleoclimate interpretations of ice cores from regions experiencing moderate summer melt rates and has the potential to give new information on temperature seasonality.

\section{ACKNOWLEDGEMENTS}

The authors thank D. B. Bahr for assistance in the Greenland field work, as well as R. Braithwaite and the Geological Survey of Greenland for logistical support, field collaboration and many helpful discussions. We also wish to thank the Swiss Federal Institute of Technology for their logistical support and M. Stober for providing GPS coordinates of EGIG-line positions. The manuscript was improved by comments from two anonymous reviewers. This work was supported by DOE grant No. DE-FG02-90ER61078 and ARO grant No. DAAHO4-96-2-0033.

\section{REFERENCES}

Alley, R. B. and S. Anandakrishnan. 1995. Variations in melt-layer frequency in the GISP2 ice core: implications for Holocene summer temperatures in central Greenland. Ann. Glaciol., 21, 64-70.

Benson, C. S. 1962. Stratigraphic studies in the snow and firn of the Greenland ice sheet. SIPRE Res. Rep. 70.

Carslaw, H. S. and J. C. Jaeger. 1959. Conduction of heat in solids. Second edition. Oxford, Clarendon Press.
Colbeck, S. C. 1979. Water flow through heterogeneous snow. Cold Reg. Sci. Technol., 1 (1), 37-45.

Colbeck, S. C. and G. Davidson. 1973. Water percolation through homogeneous snow. International Association of Scientific Hydrology Publication 107 (Symposium at Banff 1972 - The Role of Snow and Ice in Hydrology), Vol. 1, $242-257$.

Conway, H. and R. Benedict. 1994. Infiltration of water into snow. Water Resour. Res., 30 (3), 641-649.

Corey, A. T. 1977. Mechanics of heterogeneous fluids in porous media. Fort Collins, CO, Water Resources Publications.

Echelmeyer, K., W. D. Harrison, T. S. Clarke and C. Benson. 1992. Surficial glaciology of Jakobshavns Isbra, West Greenland: Part II. Ablation, accumulation and temperature. 7. Glaciol., 38(128), 169-181.

Herron, M. M., S. L. Herron and C. C. Langway, Jr. 1981. Climatic signal of ice melt features in southern Greenland. Nature, 293 (5831), $389-391$.

Hofmann, W. 1986. Bewegung des Inlandeises im West-Ost-Profil von 1959 bis 1967. In Die deutschen geodätischen Arbeiten in Rahmen der Internationalen glaziologischen Grönland-Expedition (EGIG) 1959-1974. München, Bayerische Akademie der Wissenschaften. Deutsche Geodätische Kommission, 43-61.

Illangasekare, T. H., D. N. Yates and E. J. Armbruster. 1995. Effect of heterogeneity on transport and entrapment of nonaqueous phase waste products in aquifers: an experimental study. ASCE J. Environ. Eng., 121 (8), $572-579$.

Kattelmann, R. 1989. Spatial variability of snow-pack outflow at a site in Sierra Nevada, U.S.A. Ann. Glaciol., 13, 124-128.

Koerner, R. M. and D. A. Fisher. 1990. A record of Holocene summer climate from a Canadian high-Arctic ice core. Nature, 343 (6259), 630-631.

Langway, C. C., Jr. 1967. Stratigraphic analysis of a deep ice core from Greenland. CRREL Res, Rep. 77.

Letréguilly, A., P. Huybrechts and N. Reeh. 1991. Steady-state characteristics of the Greenland ice sheet under different climates. 7. Glaciol., 37 (125), 149-157.

Marsh, P. 1991. Water flux in melting snow covers. In Corapcioglu, M. Y., ed. Advances in porous media. Vol. 1. New York, Elsevier Science Publishers, $61-124$.

Marsh, P, and M.-K. Woo. 1984. Wetting front advance and freezing of meltwater within a snow cover. 1. Observations in the Canadian Arctic. Water Resour. Res., 20 (12), 1853-1864.

Ohmura, A. and N. Reeh. 1991. New precipitation and accumulation maps for Greenland. 7. Glaciol., 37(125), 140-148.

Pfeffer, W. T. and N. F. Humphrey. 1996. Determination of timing and location of water movement and ice layer formation by temperature measurements in sub-freezing snow. F. Glaciol., 42 (141), 292-304.

Shimizu, H. 1970. Air permeability of deposited snow. Contrib. Inst. Low Temp. Sci., Ser. A 22, 1-32.

Sihvola, A. and M. Tiuri. 1986. Snow fork for field determination of the density and wetness profiles of a snow pack. IEEE Trans. Geosci. Remote Sensing, GE-24 (5), 717-721.

Steffen, C., J. Box and W. Abdalati. 1996. Greenland climate network: GCnet. CRREL Spec. Rep. 96-27, 98-103.

Wakahama, G. 1968. The metamorphism of wet snow. International Association of Scientific Hydrology Publication 79 General Assembly of Bern 1967 Snow and Ice), 370-379.

Wankiewicz, A. 1976. Water percolation within a deep snowpack - field investigations at a site on Mt. Seymour, British Columbia. (Ph.D. thesis, Interdisciplinary Program in Hydrology, University of British Columbia.)

Wankiewicz, A. 1979. A review of water movement in snow. In Colbeck, S. C. and M. Ray, eds. Modeling of Snow Cover Runoff, 26-28 September 1978, Hanover, New Hampshire. Proceedings. Hanover, NH, U.S. Army Corps of Engineers. Cold Regions Research and Engineering Laboratory, $222-252$.

Williams, M.W., M. F. Rikkers, T. Pfeffer and R. Sommerfeld. 1996. Comparison of snow liquid water measurements with a Denoth meter and Finnish snow-fork, Niwot Ridge, Colorado. [Abstract.] EOS, 77(46), Fall Meeting Supplement, F175.

Williams, R. S., Jr, D. K. Hall and C. S. Benson. 1991. Analysis of glacier facies using satellite techniques. J. Glaciol., 37 (125), 120-128. 